\title{
EFEKTIVITAS SALEP JINTAN HITAM (NIGELLA SATIVA) PADA PROSES PENYEMBUHAN LUKA PERINEUM RUPTURE IBU NIFAS
}

\author{
Yuniarti $\bowtie$ \\ Jurusan Kebidanan Poltekkes Kemenkes Palangkaraya
}

\section{ARTICLE INFO \\ Article history \\ Submitted : 2018-08-02 \\ Revised : 2018-09-21 \\ Accepted : 2018-09-27}

\section{Keywords:}

Black Cumin

Rupture Perineum

Postpartum

\begin{abstract}
The main cause of maternal mortality in Indonesia in the bearing process is infection eleven per cent of the infection come from bad treatment of perineum rupturee, there are about $85 \%$ women bearing through spontaneuous pervaginam experience perineum trauma and $1 \%$ of them are infected. The procedure of perineum treatment still uses desinfectant lotion Povidon Iodin 10\%, herbal oinment as additional wound protector and perineum pain killer, because of this, the researcher is studying the effectiveness of nigella sativa $10 \%$ and $15 \%$ in curing perineum rupture of postpartum mothers at puskesmas Jekan Raya, Central Kalimantan. Using Randomised pre-post test control group design, the 21 women suffering from perineum rupture stadium II are grouped into three. The black cumin (nigella sativa) oinment is rubbed on the wound Perineum rupture everyday during seven days of postpartum ranging from treatment group. The evaluation is done in the day 1 (pre test), the day 3 , 5 and 7 (post test) by using REEDA scale. The black cumin (nigella sativa) oinment is effective in fastening wound healing of perineum rupture compared to control group $(\mathrm{p}<0,05)$. The black cumin oinment (nigella sativa) in the inflammatory phase until the proliferation phase and can be recommended as an adjunct to the treatment of postpartum maternal perineal rupture wounds.
\end{abstract}

Corresponding Author:

Yuniarti

Jurusan Kebidanan Poltekkes Kemenkes Palangkaraya

Telp. 08125160710

Email: yuniartiamit@yahoo.com

\section{PENDAHULUAN}

Penyebab kematian maternal di Indonesia terkait persalinan adalah infeksi $11 \%$ berawal dari penatalaksanaan ruptur perineum yang kurang baik. Sekitar $85 \%$ wanita yang melahirkan spontan pervaginam mengalami trauma perineum dan kurang dari $1 \%$ Episiotomi atau ruptur perineum mengalami infeksi (Kenneth J. Leveno, 2009).

Hasil penelitian tentang luka ruptur perineum tahun 2016 dijumpai infeksi pada luka ruptur perineum pada responden sebanyak $33 \%$ di Kabupaten Murung Raya, Kalimantan Tengah (Yuniarti, 2016).

Perawatan luka ruptur perineum sangat penting dilakukan karena bisa menambah resiko terjadi infeksi pasca persalinan. Perawatan luka steril dengan menggunakan larutan normal salin dan cairan desinfektan sering disarankan untuk mencegah terjadinya luka yang bertambah parah. Selama ini obat antibiotik sering disarankan dengan dosis tertentu untuk profilaksis terjadinya infeksi pada ruptur perineum dan mencegah terjadinya sepsis pasca persalinan (Mochtar, 2007).

Cairan desinfektan yang sering digunakan pada luka ruptur perineum adalah suatu zat kimia Povidon Iodin 10\% yang punya sifat antiseptik (membunuh kuman) baik bakteri gram positif maupun negatif. Povidon Iodin $10 \%$ digunakan dalam pengaturan rumah sakit sebagai bagian dari rejimen untuk Postexposure prophylaxis (PEP). Povidon Iodin $10 \%$ dapat digunakan secara topikal untuk infeksi permukaan rektum manusia dengan efek samping perih (Perdanakusuma, 2007).

Beberapa intervensi keperawatan kepada ibu nifas dengan ruptur perineum antara lain kebersihan, mobilisasi, relaksasi, dan memberikan obat-obatan topical (spray atau salep) untuk meningkatkan penyembuhan dan 
mengurangi ketidaknyamanan luka (Kenneth J. Leveno, 2009).

Pengembangan Topical agen melalui penelitian terutama yang berasal dari bahan alami (herbal) sebagai terapi alternatif terus dilakukan yang berhubungan dengan material perawatan luka yang tersedia, material perawatan luka meliputi pembersihan, penutupan dan perlindungan terhadap luka hal tersebut mengupayakan terjadinya kondisi ideal luka supaya proses penyembuhan luka tidak mengalami gangguan (Hamilton, 1995).

Obat herbal berbentuk salep telah menarik perhatian besar dalam beberapa tahun terakhir dan semakin digunakan sebagai alternatif untuk obat-obatan kimia. Thymoquinone $(T Q)$ adalah konstituen yang paling melimpah dari minyak atsiri dari biji Jintan Hitam (Nigella Sativa) dan sebagian keunggulan Nigella sativa terutama adalah Thymoquinone. Sejumlah aktivitas farmakologis TQ telah diselidiki termasuk antioksidan, anti-inflamasi, imunomodulator, efek anti-histaminic, anti-mikroba dan anti-tumor. Bukti melaporkan dan mendukung TQ harus dikembangkan sebagai obat baru dalam uji klinis luka (Khader \& Eckl, 2014).

Berdasarkan hasil penelitian dan data dilakukan penelitian untuk mengetahui efektivitas Salep Jintan Hitam 10\% dan 15\% dalam penyembuhan luka laserasi perineum (perineum rupture) di wilayah kerja Puskesmas Jekan Raya Kalimantan Tengah.

\section{METODE PENELITIAN Desain penelitian}

Dalam penelitian ini peneliti menggunakan desain pretest-posttest control group design.

\section{Populasi dan Sampel}

Populasi dalam penelitian ini adalah seluruh ibu nifas yang dilakukan mulai bulan Juli November 2017 di wilayah kerja Puskesmas Jekan Raya Palangka Raya dengan perineum rupture yang berada diwilayah kerja Puskesmas Jekan Raya, Kalimantan Tengah sebanyak 21 ibu nifas. Pada penelitian ini terdapat 3 kelompok (1 kontrol dan 2 perlakuan), ukuran sampel dalam penelitian ini sebanyak 7 responden tiap kelompok, sehingga jumlah keseluruhan 21 responden.

\section{Pengumpulan Data}

Pembuatan Bahan Uji (bahan dan sediaan salep diperoleh dari laboratorium Universitas Lambung Mangkurat Banjar Baru) kemudian dilakukan analisis kandungan Flavonoid yang terdapat pada Salep Jintan Hitam 10\% dan 15\% yang menggunakan bahan baku Jintan Hitam dari Timur Tengah. Pengumpulan data primer pertama adalah wawancara kepada responden untuk mendapatkan data karakteristik ibu nifas meliputi pekerjaan, paritas, usia dan pendidikan. Pengumpulan data primer kedua untuk penyembuhan luka perineum dilakukan 4 kali yaitu pada hari ke-1, 3, 5, dan 7 pascasalin oleh peneliti dan enumeratur.

Pengamatan dan pengambilan data secara makroskopis pada kesembuhan luka perineum dapat dilakukan dengan pengukuran diameter/luas luka dan menggunakan formulir Skala REEDA yang berisi lima item pemeriksaan penyembuhan luka perineum yaitu redness, oedema, ecchymosis, discharge, dan approximation pada hari perawatan pertama, ketiga, kelima dan ketujuh. Hari ke-1 pemeriksaan luka perineum untuk melihat kondisi umum perineum sebelum ibu pulang. Pada hari ke-3 pemeriksaan terhadap kemungkinan infeksi luka perineum. Hari ke-5 pemeriksaan terhadap kemungkinan luka terbuka. Hari ke-7 melihat penyembuhan luka perineum.

\section{Teknik Analisis data}

Metode analisis menggunakan uji normalitas data dengan uji Shapiro Wilk $(\mathrm{p}<0,05)$ karena ukuran sampel $<50$. Uji homogenitas menggunakan Test of Homogeneity of Variance $(\mathrm{P}<0,05)$. Uji Repeated Measures ANOVA $(\mathrm{p}<0,05)$.

\section{HASIL PENELITIAN}

Tabel 1 menunjukkan data pendidikan responden pada kelompok intervensi 1 masingmasing sebanyak 2 responden (33,3\%) memiliki pendidikan SD, SMP, dan SMA. Pada kelompok intervensi 2 responden terbanyak memiliki tingkat pendidikan SMA yaitu 6 responden $(85,7 \%)$, dan pada kelompok kontrol responden terbanyak berpendidikan SMA yaitu 3 responden $(42,9 \%)$ dengan nilai $\mathrm{p}$ value $0,122>0,005$ artinya tidak ada perbedaan signifikan pendidikan pada masing-masing kelompok. 
Tabel 1. Karakteristik Responden berdasarkan Pendidikan dan Paritas Ibu Nifas

\begin{tabular}{lccccccc}
\hline \multirow{2}{*}{ Karakteristik } & $\begin{array}{c}\text { Kelompok } \\
\text { Intervensi 1 }\end{array}$ & \multicolumn{2}{c}{$\begin{array}{c}\text { Kelompok } \\
\text { Intervensi 2 }\end{array}$} & $\begin{array}{c}\text { Kelompok } \\
\text { Kontrol }\end{array}$ & $\begin{array}{c}\text { Uji } \\
\text { Beda }\end{array}$ \\
\cline { 2 - 8 } & $\mathbf{n}$ & $\mathbf{( \% )}$ & $\mathbf{n}$ & $\mathbf{\%}$ & $\mathbf{n}$ & $\mathbf{\%}$ & p value \\
\hline Pendidikan & & & & & & & \\
SD & 2 & 33,3 & 1 & 14,3 & 0 & 0,0 & \\
SMP & 2 & 33,3 & 0 & 0,0 & 2 & 28,6 & 0,122 \\
SMA & 2 & 33,3 & 6 & 85,7 & 3 & 42,9 & \\
PT & 0 & 0,0 & 0 & 0,0 & 2 & 28,6 & \\
Jumlah & 6 & 100 & 7 & 100 & 7 & 100 & \\
\hline Paritas & & & & & & & \\
Primipara & 1 & 16,7 & 1 & 14,3 & 2 & 28,6 & \\
Multipara & 4 & 66,7 & 6 & 85,7 & 5 & 71,4 & 0,609 \\
Grande multipara & 1 & 16,7 & 0 & 0,0 & 0 & 0,0 & \\
Jumlah & 6 & 100 & 7 & 100 & 7 & 100 & \\
\hline
\end{tabular}

Berdasarkan tabel 2, penyembuhan luka perineum pada kelompok intervensi 1 dan kelompok kontrol didapatkan pada hari ke-3 p value 0,079 artinya tidak ada perbedaan yang signifikan pada penyembuhan luka perineum. Pada hari ke-5 didapatkan nilai $\mathrm{p}$ value 0,079 artinya tidak ada perbedaan yang signifikan pada penyembuhan luka. Sedangkan pada hari ke-7 nilai $\mathrm{p}$ value 0,035 artinya ada perbedaan yang signifikan pada penyembuhan luka perineum ibu nifas pada setiap kelompok.

Tabel 2. Perbedaan Efektivitas Penyembuhan Luka Perineum Kelompok Intervensi 1 dan Kelompok Kontrol pada Ibu Nifas di Wilayah Kerja Puskesmas Jekan Raya Palangka Raya Tahun 2017 (n = 20)

\begin{tabular}{cc}
\hline \multirow{2}{*}{ Hari } & p value \\
\cline { 2 - 2 } & Luka \\
\hline ke-3 & 0,079 \\
ke-5 & 0,079 \\
ke- & 0,035 \\
\hline
\end{tabular}

Berdasarkan tabel 3, penyembuhan luka perineum pada kelompok intervensi 2 dan kelompok kontrol didapatkan pada hari ke-3 p value 0,174 artinya tidak ada perbedaan yang signifikan pada penyembuhan luka perineum.
Pada hari ke-5 didapatkan nilai $\mathrm{p}$ value 0,091 artinya tidak ada perbedaan yang signifikan pada penyembuhan luka. Sedangkan pada hari ke-7 nilai $p$ value 0,000 artinya ada perbedaan yang signifikan pada penyembuhan luka.

Tabel 3. Perbedaan Efektivitas Penyembuhan Luka Perineum Kelompok Intervensi 2 dan Kelompok Kontrol pada Ibu Nifas di wilayah kerja Puskesmas Jekan Raya Palangka Raya Tahun 2017 (n = 20)

\begin{tabular}{cc}
\hline \multirow{2}{*}{ Hari } & p value \\
\cline { 2 - 2 } ke-3 & Luka \\
ke-5 & 0,174 \\
ke-7 & 0,091 \\
\end{tabular}




\section{PEMBAHASAN}

Karakteristik ibu nifas pada penelitian ini terbanyak memiliki pendidikan SMA bukan merupakan variabel perancu dalam penyembuhan luka perineum. Responden sebagian besar adalah multipara dengan hasil analisis hubungan status obstetri didapatkan responden primipara dengan tanda REEDA hasil uji statistik menunjukkan tidak ada hubungan yang signifikan faktor status obstetri dengan penyembuhan luka perineum.

Hasil analisa data uji Mann Whitney- $U$ kelompok intervensi 1 (menggunakan salep jintan hitam 10\%) dan kelompok kontrol, kelompok intervensi 2 (menggunakan salep jintan hitam 15\%) dan kelompok kontrol ditemukan pada hari ke-7 menunjukkan perbedaan signifikan pada penyembuhan luka perineum dengan ( $\mathrm{p}$ value $<0,05$ ). Hasil tersebut menyatakan bahwa hipotesis penelitian diterima yang artinya proses penyembuhan luka perineum rupture pada kelompok yang ditambahkan salep jintan hitam (10\% dan 15\%) sebagai pendamping antiseptik pada perawatan luka lebih cepat dari pada kelompok kontrol. Terbukti bahwa pemberian salep jintan hitam membantu mempercepat proses penyembuhan luka, sejak fase inflamasi hingga pada fase proliferasi.

Hasil penelitian ini sejalan dengan penelitian sebelumnya dalam konteks perawatan luka penyembuhan dengan perlakuan Nigella sativa dalam sediaan krim efektif dalam memberikan kesembuhan terlihat pada perawatan hari ke-4, ke-9 dan ke-14 ( $<<0,001)$ (Yaman, Durmus, Ceribasi, \& Yaman, 2010).

Hasil penelitian lain ditemukan bahwa terdapat perbedaan dalam proses penyembuhan luka ulkus diabetik menggunakan ekstrak binahong (kadar flavonoid total 1,10\%+0,53\%) dimana terjadi peningkatan jaringan epitel dan kolagen yang disertai penurunan jumlah pembuluh darah baru, perbaikan penyembuhan luka semakin meningkat seiiring meningkatnya dosis ekstra etanol binahing yang diberikan. Sejalan dengan penelitian yang dilakukan peneliti dimana ekstra jintan hitam (Nigella Sativa) yang menggandung flavonoid total dengan kadar 21,22 +0,64 $\mu / \mathrm{mg}$ ekstrak (Nurul Firdausi, 2015).

Sejalan dengan hasil penelitian Gupta \& Chaphalkar tahun 2016 bahwa adanya aktivitas anti inflamasi dan imunosupresif pada tanaman obat dimana semua flavonoid pada dosisi tinggi menunjukkan penurunan yang signifikan dalam priliferasi, produksi nitric oxide (NO) dan permukaan CD14 dimana efek penghambatan terjadi setelah 48 jam pemberian. Flavonoid yang diekstrasi dari tanaman pada penelitian ini adalah 0,5 - 10 $\mathrm{mg} / \mathrm{mL} ; 50 \mu \mathrm{l}$ (Gupta \& Chaphalkar, 2016).

\section{KESIMPULAN}

Berdasarkan hasil penelitian, bahwa proses penyembuhan luka perineum rupture pada kelompok yang diberikan salep jintan hitam sebagai pendamping antiseptik pada perawatan luka lebih cepat daripada kelompok yang tidak diberikan salep jintan hitam diukur dengan Skala REEDA. Lamanya proses penyembuhan luka (hari) karena kandungan flavonoid pada ekstra jintan hitam (Nigella Sativa) pada penelitian ini dengan kadar yang mampu memberikan efek peningkatan jaringan epitel dan kolagen yang disertai penurunan jumlah pembuluh darah baru, perbaikan penyembuhan luka semakin meningkat seiring meningkatnya dosis yang diberikan, sehingga salep jintan hitam dapat dijadikan rekomendasi sebagai tambahan perawatan luka ruptur perineum ibu nifas.

\section{UCAPAN TERIMA KASIH}

Terima kasih disampaikan kepada pengelola Jurnal Kesehatan Manarang yang berkenan mendukung publikasi penelitian ini, dan kepada Kepala Puskesmas serta rekan-rekan Bidan di Puskesmas Jekan Raya Kota Palangka Raya Kalimantan Tengah dan ibu-ibu nifas yang berpartisipasi dalam penelitian ini.

\section{DAFTAR PUSTAKA}

Gupta, A., \& Chaphalkar, S. R. (2016). Antiinflammatory and immunosuppressive activities of flavonoids from medicinal plants, 5(3), 120-124.

Hamilton, P. M. (1995). Dasar-dasar Keperawatan Maternitas. (EGC, Ed.) (6th ed.). Jakarta.

Kenneth J. Leveno. (2009). Obstetri Williams : Panduan Ringkas (21st ed.). Jakarta: EGC.

Khader, M., \& Eckl, P. M. (2014). Thymoquinone: An emerging natural drug with a wide range of medical applications. Iranian Journal of Basic Medical Sciences.

Mochtar, R. (2007). Sinopsis Obstetri Fisiologi 
Patologi (III). Jakarta: EGC.

Nurul Firdausi, R. (2015). Pengaruh Ekstrak Etanol Binahong (Anredera Cordifolia) Terhadap Profil Histopatologi Penyembuhan Luka Tikus Wistar Jantan Yang Diinduksi Aloksan. repository unej. Perdanakusuma. (2007). Course Book. One Day Interactive Course. Evidence-Based Wound Care Management From Evidence To Therapy. Jurnal Ilmu Bedah Indonesia. Yogyakarta: IKABI.
Yaman, I., Durmus, a S., Ceribasi, S., \& Yaman, M. (2010). Effects of Nigella sativa and silver sulfadiazine on burn wound healing in rats. International Journal for Veterinary and Biomedicinal Science, 55(12), : 619-624.

Yuniarti. (2016). Efektivitas Salep Jintan Hitam (Nigella Sativa) Pada Proses Penyembuhan Luka Perineum Rupture Ibu Nifas. Jurnal Forum Kesehatan, VI, 26-35. 